\title{
Electrochemical Behavior of Plasma-Sprayed Stainless Steel
}

\author{
Anushraj B, Winowlin Jappes J T, Adam Khan M, Dillibabu V and Brintha N C
}

\begin{abstract}
The effect of electrochemical behavior of plasma sprayed $\mathrm{NiCr}-\mathrm{Cr}_{2} \mathrm{O}_{3}(80: 20)$ and $\mathrm{Al}_{2} \mathrm{O}_{3}-40 \% \mathrm{TiO}_{2}$ as coating on stainless steel $316 \mathrm{~L}$ were investigated. The polarization studies were carried out in $1.0 \mathrm{M} \mathrm{H}_{2} \mathrm{SO}_{4}$ and $3.5 \% \mathrm{NaCl}$ solution as a corrosive medium. The corrosion potential is more positive in the coated sample and gives good corrosion resistance when compared to bare sample. The surface characterization studies were carried out through electron microscope attached with energy dispersive spectroscopy. It was found that intergranular attack and pitting corrosion takes place in the sample exposed in $1.0 \mathrm{M} \mathrm{H}_{2} \mathrm{SO}_{4}$ and large crater was found in the sample exposed in $3.5 \% \mathrm{NaCl}$ solution.
\end{abstract}

Keywords : Corrosion, Coating, polarization

\section{INTRODUCTION}

$\mathrm{S}_{\mathrm{t}}$ ainless steel found wide application in medical and surgical equipments, chemical industry, paramedical and food industry. There are several types of stainless steel they are austenitic stainless steels, ferritic stainless steels, duplex and super duplex stainless steels. Yin et.al [1] evaluated that the ferritic and martensitic steels when exposed to $600^{\circ} \mathrm{C}$ corrosion rate was high. Also in the grain boundaries oxide film was formed and minor cracks are formed on the surface of the sample. Zhang et.al [2] reported that nodular corrosion takes place in the stainless steel (SS316L) in super critical water. Xu et.al [3] investigated the corrosion behavior of stainless steel in super critical water and founds that corrosion rate is increased with the increase in temperature and coefficient of oxidation.

Thermal spraying coating produces the spalling of splats due to their low bonding of the substrate $[4,5]$. High velocity oxygen fuel (HVOF) spraying improves the porosity of the coating [6]. The remelting of substrate improves the corrosion resistance of the substrate when it is exposed in corrosive medium [7]. The oxides and metallic coatings of the substrate

Revised Manuscript Received on December 5, 2019

* Correspondence Author

Anushraj B, Centre for Surface Engineering, Department of Mechanical Engineering, Kalasalingam Academy of Research \& Education, Virudhunagar, Tamilnadu, India Email: anushrajb@gmail.com

Winowlin Jappes J T, Centre for Surface Engineering, Department of Mechanical Engineering, Kalasalingam Academy of Research \& Education, Virudhunagar, Tamilnadu, India Email: winowlin@klu.ac.in

Adam Khan $\mathbf{M}^{*}$, Centre for Surface Engineering, Department of Mechanical Engineering, Kalasalingam Academy of Research \& Education, Virudhunagar, Tamilnadu, India, Email: adamkhanm@gmail.com

Dillibabu V, Scientist, Small Turbo Fan Section, Gas Turbine Research Establishment (GTRE), DRDO, Bangalore, India. Email: dilli.drdo@gmail.com

Brintha N C, Department of Computer Science and Engineering, Kalasalingam Academy of Research and Education, Virudhunagar, Tamilnadu, India. Email: brinthachris2k@gmail.com define the mechanical and chemical properties of the uncoated sample [8]. The oxides such as $\mathrm{ZrO}_{2}, \mathrm{Cr}_{2} \mathrm{O}_{3}, \mathrm{Al}_{2} \mathrm{O}_{3}$, $\mathrm{TiO}_{2}$, etc are source materials used as surface coating $[9,10]$. The plasma spray coating is best suited for thermal barrier coating materials [11].

Mahesh et al [12] investigated the hot corrosion behaviour of NiCrAl coating deposited on Ni- and Fe-based superalloy substrates by using $\mathrm{HVOF}$ process in molten salt environment $\left(\mathrm{Na}_{2} \mathrm{SO}_{4}-60 \% \mathrm{~V}_{2} \mathrm{O}_{5}\right)$ at $900^{\circ} \mathrm{C}$ under cyclic conditions. The mass gain measurements were also performed after each cycle to establish the kinetics of corrosion using thermogravimetric technique. The results showed that the bare superalloys experienced higher weight gain. The NiCrAl-coated Superni 750 alloy (SN 750) provided a better protection among the coated superalloys. The formation of oxides and spinels of nickel, chromium and aluminum believed to have contributed for better resistance to hot corrosion.

In this investigation, the stainless steel of $316 \mathrm{~L}$ is coated with $\mathrm{NiCr}-\mathrm{Cr}_{2} \mathrm{O}_{3}$ (80:20) and $\mathrm{Al}_{2} \mathrm{O}_{3}-40 \% \mathrm{TiO}_{2}$ by plasma spray coating. The coated samples and uncoated samples are exposed to $1.0 \mathrm{M} \mathrm{H}_{2} \mathrm{SO}_{4}$ and $3.5 \% \mathrm{NaCl}$ solution to evaluate the corrosion resistance of the substrate.

\section{EXPERIMENTAL SETUP}

The chemical composition of stainless steel used in this experimental investigation is listed in table I. The samples are coated with plasma coating with having $\mathrm{NiCr}-\mathrm{Cr}_{2} \mathrm{O}_{3}$ (80:20) and $\mathrm{Al}_{2} \mathrm{O}_{3}-40 \% \quad \mathrm{TiO}_{2}$ as a feed stock material. The parameters used for coating is listed in table II. The coating was carried out at room temperature. The thickness of the coating varies from 250-300 micron. The electro chemical behavior of stainless steel with and without coating was carried out in $1.0 \mathrm{M} \mathrm{H}_{2} \mathrm{SO}_{4}$ and $3.5 \% \mathrm{NaCl}$ Solution.

Table I: Chemical Composition of Stainless Steel

\begin{tabular}{|l|l|l|l|l|l|l|l|l|l|}
\hline Element & $\mathrm{Ni}$ & $\mathrm{Cr}$ & $\mathrm{Mo}$ & $\mathrm{S}$ & $\mathrm{Si}$ & $\mathrm{Mn}$ & $\mathrm{C}$ & $\mathrm{P}$ & $\mathrm{Fe}$ \\
\hline Weight \% & 12 & 17 & 2.5 & 0.03 & 1 & 2 & 0.08 & 0.045 & bal \\
\hline
\end{tabular}

Potentiostat is used to measure electrochemical polarization. It consists of three electrodes which is arranged with the sample as a working electrode, platinum electrode as counter electrode and calomel electrode as the reference electrode. The measurement procedure is adopted as per ASTM G3-14 standard. The exposure area is $1 \mathrm{~cm}^{2}$ in room temperature. The sample with and without coating is exposed in $3.5 \% \mathrm{NaCl}$ solution and $1.0 \mathrm{M} \mathrm{H}_{2} \mathrm{SO}_{4}$ solution. 
The sweep voltage is set to -250 to $250 \mathrm{mV}$ after the open circuits get stabled at a sweep rate of $1 \mathrm{mV} / \mathrm{sec}$. The electrochemical polarization measurement is done through TAFEL plot. The electron microscope attached with energy dispersive spectroscopy is used to study the characterization of the exposed material.

Table II: Parameters used for Atmospheric Plasma Coating

\begin{tabular}{|l|l|l|}
\hline Spraying condition & Parameters & Units \\
\hline Plasma Arc Current & $450-500$ & A \\
\hline Arc Voltage & $60-70$ & $\mathrm{~V}$ \\
\hline Plasma Gas (Argon) & $1.3-1.5$ & $(\mathrm{x} 10-3) \mathrm{m}^{3} / \mathrm{s}$ \\
\hline Secondary Gas (Hydrogen) & $0.3-0.4$ & $(\mathrm{x} 10-3) \mathrm{m}^{3} / \mathrm{s}$ \\
\hline Powder feed rate & $0.66-0.83$ & $\mathrm{~g} / \mathrm{s}$ \\
\hline Torch to base distance & $76-125$ & $\mathrm{~mm}$ \\
\hline
\end{tabular}

\section{RESULTS AND DISCUSSION}

\section{A. Behavior of Corrosion in $1.0 \mathrm{M} \mathrm{H} \mathrm{H}_{2} \mathrm{SO}_{4}$}

\section{1) Electrochemical Polarization Test}

The influence of with and without coated samples are subjected to electrochemical corrosion study. Figure 1 shows the polarization graph obtained for surface exposed in $1.0 \mathrm{M}$ $\mathrm{H}_{2} \mathrm{SO}_{4}$. From the graph it is confirmed that the bare stainless steel have high corrosion due to the current density is high. In the $\mathrm{NiCr}-\mathrm{Cr}_{2} \mathrm{O}_{3}$ the current density is low also when compared to bare sample corrosion potential is high. Nickel chromium coating in the stainless steel gives good corrosion resistance since these two elements is acts as corrosion barrier. The $\mathrm{Al}_{2} \mathrm{O}_{3}$ coating also has better corrosion resistance when compared to bare sample and low corrosion resistance to nickel chromium coating.

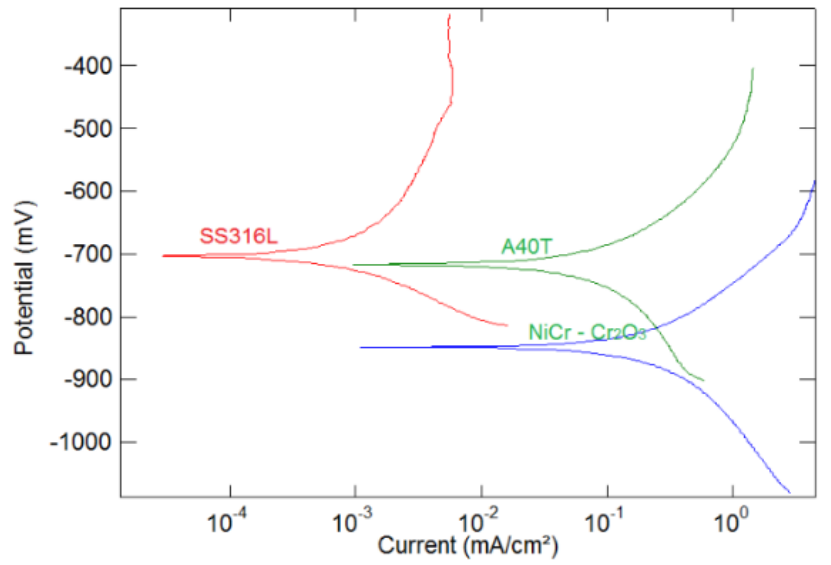

Fig 1: Polarization graph obtained by the sample exposed to $1.0 \mathrm{M} \mathrm{H}_{2} \mathrm{SO}_{4}$

2) Surface Analysis

The coated and uncoated sample exposed to $1.0 \mathrm{M} \mathrm{H}_{2} \mathrm{SO}_{4}$ was subjected to surface analysis is shown in figure 2 . The bare sample exposed in $1.0 \mathrm{M} \mathrm{H}_{2} \mathrm{SO}_{4}$ was found intergranular attack and pitting takes place. Due to both the corrosion mechanism takes place in the sample corrosion is high and it is clearly confirmed in the electrochemical analysis. The $\mathrm{Al}_{2} \mathrm{O}_{3}$ coated samples descaling takes place on the sample and coating is act as barrier to corrosion. The $\mathrm{NiCr}-\mathrm{Cr}_{2} \mathrm{O}_{3}$ -coating is act as protective layer to improve the corrosion resistance.

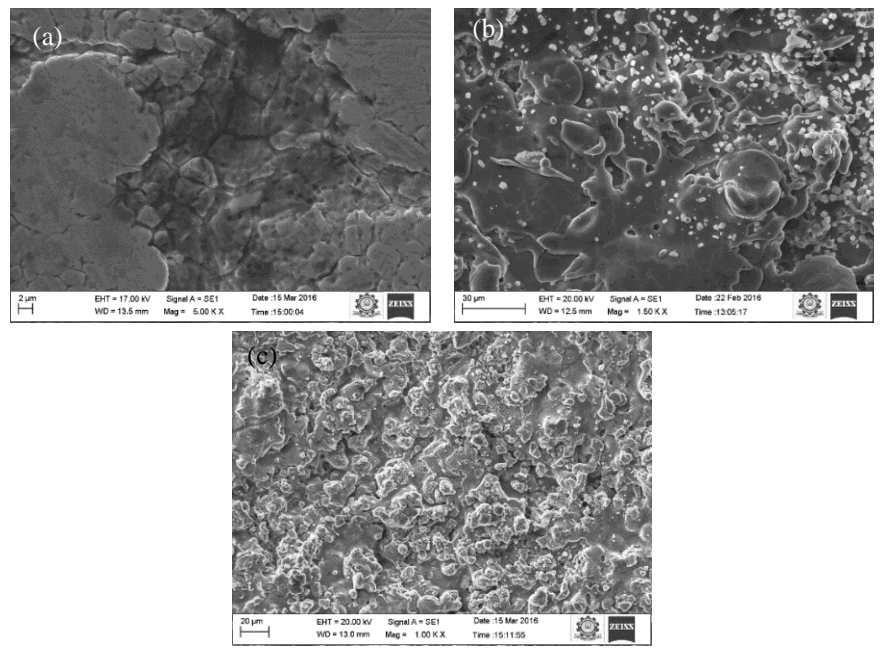

Fig 2: SEM image of Sample exposed in $1.0 \mathrm{M} \mathrm{H}_{2} \mathrm{SO}_{4}$ Solution (a) Bare (b) $\mathrm{Al}_{2} \mathrm{O}_{3}-\mathrm{TiO}_{2}$ (c) $\mathrm{NiCr}-\mathrm{Cr}_{2} \mathrm{O}_{3}$

Figure 3 shows the element distribution of sample exposed in $1.0 \mathrm{M} \mathrm{H}_{2} \mathrm{SO}_{4}$. The segregation of iron element is more in the bare sample, $\mathrm{Al}_{2} \mathrm{O}_{3}$ coated sample the segregation of aluminium is high and nickel chromium coated sample the segregation of chromium is high. From the element distribution it clearly confirmed that the chromium and aluminium is act as corrosion resistance element.
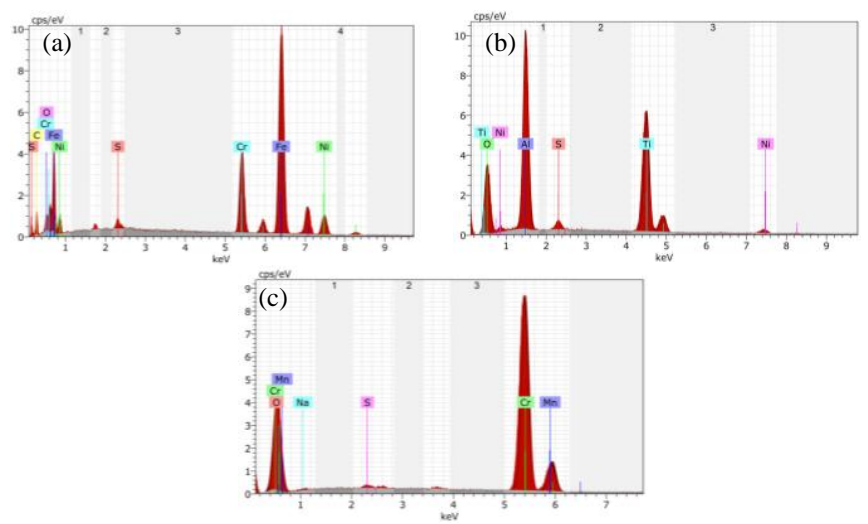

Fig 3: Element Distribution of Sample Exposed in 1.0M $\mathrm{H}_{2} \mathrm{SO}_{4}$ Solution (a) Bare (b) $\mathrm{Al}_{2} \mathrm{O}_{3}-\mathrm{TiO}_{2}$ (c) $\mathrm{NiCr}-\mathrm{Cr}_{2} \mathrm{O}_{3}$

\section{B. Behavior of Corrosion in $3.5 \% \mathrm{NaCl}$ solution}

1) Electrochemical Polarization Test

The Figure 4 infers the graph obtained from the electrochemical analysis of sample exposed in $3.5 \% \mathrm{NaCl}$ solution. The nickel chromium coated sample has good corrosion when compare to bare sample and aluminum coated sample. The nickel coated sample has low current density and more positive corrosion potential due to the reason the corrosion resistance is increased. The bare sample has high current density whereas $\mathrm{Al}_{2} \mathrm{O}_{3}$ coated sample has low current density. The $\mathrm{Al}_{2} \mathrm{O}_{3}$ coated sample and bare sample has more negative corrosion potential when compared to nickel-chromium coated sample. 


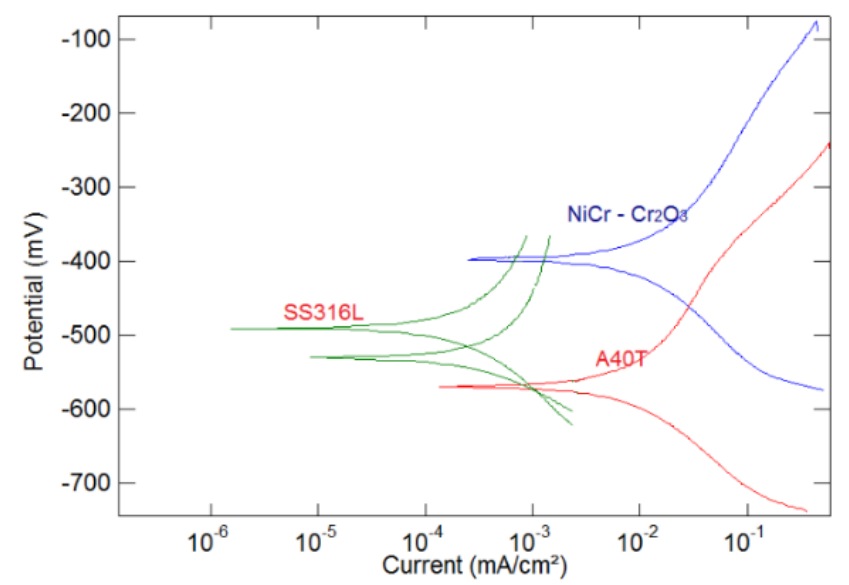

Fig 4: Polarization graph obtained by the sample exposed to $3.5 \% \mathrm{NaCl}$

Figure 5a shows the SEM image shows the bare sample exposed in $3.5 \% \mathrm{NaCl}$ Solution. The sample exposed in $3.5 \%$ of $\mathrm{NaCl}$ solution the crater takes place in the surface. The SEM image aluminum oxide coated sample exposed in sodium chloride solution is shown in figure $5 \mathrm{~b}$. The oxides are formed on the surface of the sample. These oxides may act as a protective layer to the sample. The SEM image of nickel chromium coating the sodium salts are present on the surface of the sample is shown in the figure $5 \mathrm{c}$.

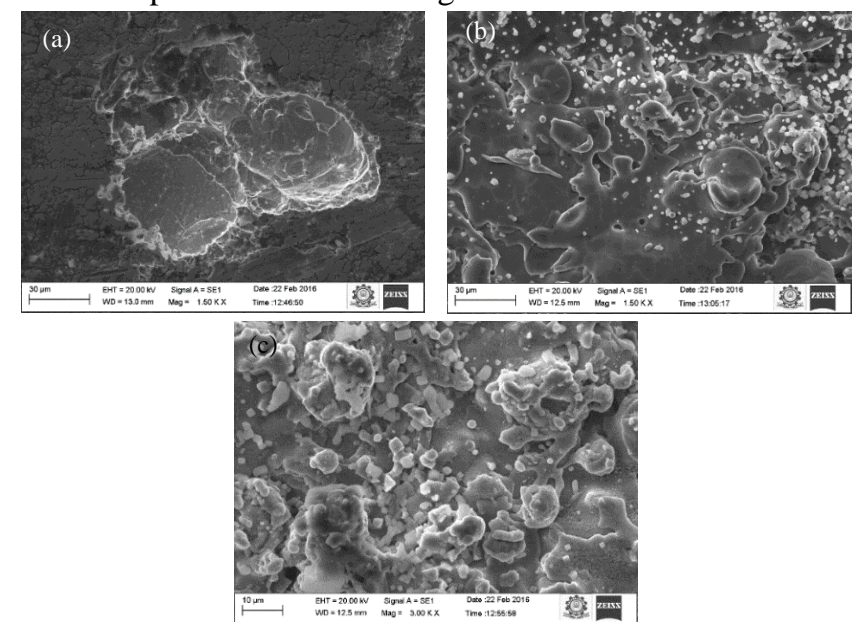

Fig 5: SEM image of Sample Exposed in 3.5\% NaCl Solution (a) Bare (b) $\mathrm{Al}_{2} \mathrm{O}_{3}-\mathrm{TiO}_{2}$ (c) $\mathrm{NiCr}-\mathrm{Cr}_{2} \mathrm{O}_{3}$

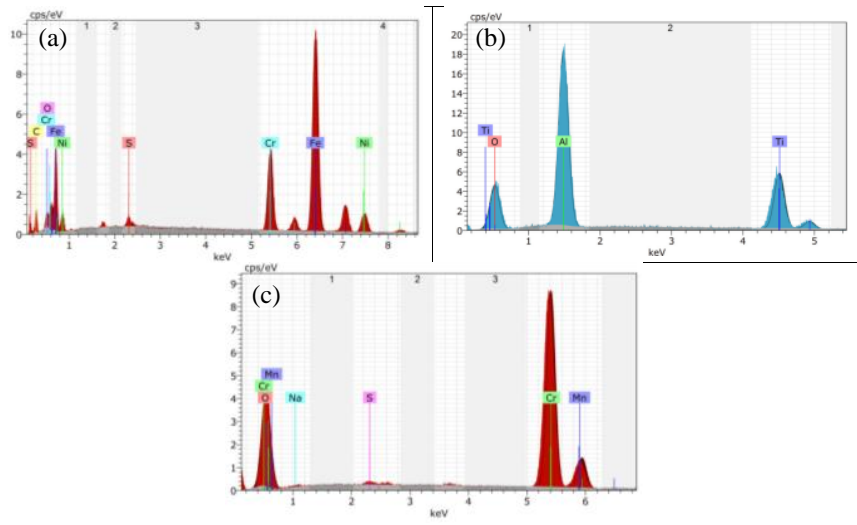

Fig 6: Element Distribution of Sample Exposed in 3.5\% $\mathrm{NaCl}$ Solution (a) Bare (b) $\mathrm{Al}_{2} \mathrm{O}_{3}-\mathrm{TiO}_{2}$ (c) $\mathrm{NiCr}-\mathrm{Cr}_{2} \mathrm{O}_{3}$

The element distribution of sample exposed in $3.5 \% \mathrm{NaCl}$ solution is shown in figure 6 . The bare sample exposed in
$\mathrm{NaCl}$ solution the segregation of iron element is high due to this anodic dissolution is takes place. This anodic dissolution reduces the corrosion resistance of the sample. The aluminium coated sample aluminium oxide segregation is high which act as the corrosion resistance to the sample. The nickel chromium coated sample the element chromium and magnesium segregation is high which gives good corrosion resistance.

\section{CONCLUSIONS}

In this work the electrochemical behavior of stainless steel with coating of $\mathrm{Al}_{2} \mathrm{O}_{3}-\mathrm{TiO}_{2}$ and $\mathrm{NiCr}-\mathrm{Cr}_{2} \mathrm{O}_{3}$ exposed in $1.0 \mathrm{M} \mathrm{H}_{2} \mathrm{SO}_{4}$ and $3.5 \% \mathrm{NaCl}$ solution were investigated. The conclusions are summarized as follows:

- The stainless steel $316 \mathrm{~L}$ is corrosive resistance up to a thrust hold value. The bare metal has undergone grain boundaries attack and deteriorate fast in acidic medium.

- In $\mathrm{NiCr}-\mathrm{Cr}_{2} \mathrm{O}_{3}$ coated sample has observed with scaling of oxides with micro pores in both the corrosive medium. Alumina - titania coatings possess good surface resistance to acidic and alkalinity medium.

- The $\mathrm{NiCr}-\mathrm{Cr}_{2} \mathrm{O}_{3}$ coated sample gives good corrosion resistance when exposed in both the corrosive medium.

\section{REFERENCES}

1. Yin KJ, Qiu SY, Tang R, Zhang Q, Zhang LF. Corrosion behavior of ferritic/martensitic steel P92 in supercritical water. J Supercrit Fluids 2009;50(3):235-9.

2. Zhang Q, Tang R, Cong LI, Luo X, Long C. Corrosion behavior of Ni-base alloys in supercritical water. Nucl Eng Technol 2009;41(1):107-12

3. Xu DH, Ma ZJ, Guo SW, Tang XY, Guo Y, Wang SZ. Corrosion characteristics of $316 \mathrm{~L}$ as transpiring wall material in supercritical water oxidation of sewage sludge. Int $\mathrm{J}$ Hydrogen Energy 2017;42(31):19819-28.

4. H. Yun, W. Zhang, H. Wang, Y. Guo, M. Wei, Z. Song, Y. Wang, Bonding and sliding wear behaviors of the plasma sprayed $\mathrm{NiCrBS}$ coatings, Tribol. Int. 66 (2013) 105-113.

5. L. Liu, H. Xu, J. Xiao, X. Wei, G. Zhang, C. Zhang, Effect of heat treatment on structure and property evolutions of atmospheric plasma sprayed NiCrBSi coatings, Surf. Coat. Technol. 325 (2017) 548-554.

6. Planche, M. P., Liao, H., Normand, B., \& Coddet, C. (2005). Relationships between $\mathrm{NiCrBSi}$ particle characteristics and corresponding coating properties using different thermal spraying processes. Surface and Coatings Technology, 200(7), 2465-2473.

7. Houdková, Š., Smazalová, E., Vostřák, M., \& Schubert, J. (2014) Properties of NiCrBSi coating, as sprayed and remelted by different technologies. Surface and Coatings Technology, 253, 14-26.

8. Y. Wang, M.X. Li, H.L. Suo, Mechanical properties of YSZ thermal barrier coatings with segmented structure. Surf. Eng. 28(5), 329-333 (2012)

9. M. Srivastava, J.N. Balaraju, B. Ravishankar, K.S. Rajam, Improvement in the properties of nickel by nano-Cr2O3 incorporation. Surf. Coat. Technol. 205, 66-75 (2010)

10. K. Kumar, R. Chandramohan, D. Kalyanaraman, Effect of heat treatment on cobalt and nickel electroplated surfaces with $\mathrm{Cr} 2 \mathrm{O} 3$ dispersions. Appl. Surf. Sci. 227, 383 (2004)

11. M. Adam Khan, S. Sundarrajan, S. Natarajan, Influence of plasma coatings on Inconel 617 for gas turbine applications. Surf. Eng. 30(9), 656-661 (2014)

12. R.A. Mahesh, R. Jayaganthan, S. Prakash, Evaluation of hot corrosion behaviour of $\mathrm{HVOF}$ sprayed $\mathrm{Ni}-5 \mathrm{Al}$ and $\mathrm{NiCrAl}$ coatings in coal fired boiler environment. Surf. Eng. 26(6), 413-421 (2010) 


\section{AUTHORS PROFILE}

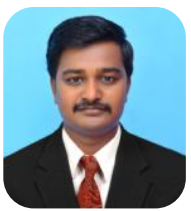

Mr. Anushraj B graduated in 2012 from St.Xavier's Catholic College of Engineering, India. In 2014, he received his M.E Degree in Energy Engineering from Regional Campus of Anna University, Tirunelveli, India. Currently, he is a research scholar at Kalasalingam Academy of Research and Education, India.

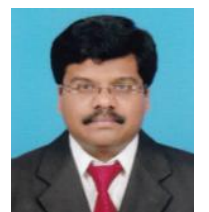

Dr. Winowlin Jappes J T graduated in 1997 from Manonmaniam Sunderanar University, India in Mechanical Engineering. In 1999, he has completed his masters in Production Engineering from Annamalai University. He completed his Ph.D degree in 2004 in the area of Composite Deposition at Indian Institute of Technology Madras, Chennai. He has completed three DST funded research projects and published more than 125 research articles which include 65 International Journal papers. Currently, he is working as Senior Professor in Kalasalingam University, India. His research interest includes high performance composite materials, machining of hard materials, optimization techniques, etc. At present, he is working as Professor and Dean, School of Automotive and Mechanical Engineering, Kalasalingam Academy of Research and Education, India.

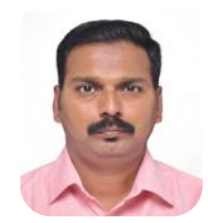

Dr. Adam Khan $\mathbf{M}$ is a Post-Doctoral Researcher from the Department of Mechanical and Industrial Engineering Technology, University of Johannesburg, South Africa. He received his Doctoral Degree from National Institute of Technology, Tiruchirappalli, India for his research in Surface Engineering studies on high temperature materials. His Bachelor (B.E.) and Master Degree (M.E.) from Anna University, Chennai in the specialization of Production and Design. Dr. Adam Khan research is focused on surface engineering and metallurgical analysis on processed materials. He has published 38 technical articles in different journals of international repute.

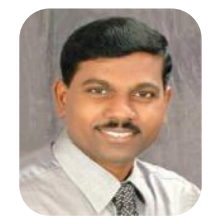

Dr. Dillibabu V received his Doctoral Degree from National Institute of Technology, Tiruchirappalli, India. Currently, he is a scientist at Gas Turbine Research Establishment, DRDO, Bangalore.

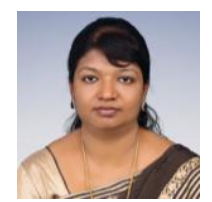

Dr. Brintha N C graduated in 2002 from Manonmaniam Sunderanar University, India. In 2006 , she received her M.E Degree with distinction in Computer Science and Engineering from A.K.C.E, Anna University, Chennai. She completed her P.hd degree in 2018 in the area of Cloud Manufacturing under Anna University, Chennai. Currently, she is working as Associate professor/ CSE in Kalasalingam Academy of Research and Education, India. Her research interests include Cloud computing, Optimization, Scheduling, Cloud Manufacturing and so forth. 